\title{
Demographic Profile of Patients Undergoing Colonoscopy at a Tertiary Care Centre in Central Nepal
}

\author{
Narayan Prasad Belbase, ${ }^{1}$ Mukesh Karki, ${ }^{1}$ Kush Raj Dewan, ${ }^{2}$ Rohit Mishra' \\ 'Department of Surgical Gastroenterology, College of Medical Sciences, Bharatpur, Chitwan, ${ }^{2}$ Department of Medical \\ Gastroenterology, College of Medical Sciences, Bharatpur, Chitwan.
}

\section{ABSTRACT}

\section{Introduction}

Colonoscopy is one of the useful diagnostic tool to evaluate lower gastrointestinal tract. The aim of this study was to evaluate patient characteristics, common symptoms, colonoscopic findings and histopathology findings by reviewing colonoscopy procedures.

\section{Methods}

This was a retrospective study conducted at College of Medical Sciences and teaching hospital, Bharatpur, Nepal over a period of three years (January 1st 2017 -December 31st 2019). Ethical clearance was taken from institutional review committee. Census sampling method was used to retrieve the data.

\section{Results}

Over a three years period 324 colonoscopy were reviewed.The mean age of the study population was $48.77+/-17.35$ years. Male to female ratio was 1.38:1. The most common indication for colonoscopy was pain abdomen with mucus in stool in $25.3 \%$ patients followed by bleeding per rectum in $21.3 \%$ patients. Other than normal colonoscopy the most common findings were Haemorrhoids in $20.1 \%$ patients and inflammatory or ulcerative lesions in $17.6 \%$ patients. Colorectal malignancy was seen in $6.48 \%$ patients. Colonoscopic biopsy was done in 114 patients. The common biopsy findings were ulcerative colitis in $12.7 \%$, adenomatous polyp in $6.8 \%$, adenocarcinoma in $6.5 \%$ of the total study patients.Poorly differentiated carcinoma was found more in the younger age group and males were more commonly affected with colorectal cancers than females.

\section{Conclusions}

The most common indication for colonoscopy was pain abdomen with mucus in stool in $25.3 \%$ patients. The common findings were Haemorrhoids in $20.1 \%$ patients and inflammatory or ulcerative lesions in $17.6 \%$ patients. Colorectal malignancy was seen in $6.48 \%$ patients. The common biopsy findings were ulcerative colitis in $12.7 \%$, adenomatous polyp in $6.8 \%$, adenocarcinoma in $6.5 \%$ of the total study patients. Males were more commonly affected with colorectal cancers than females.

Key words: colonoscopy; lower gastrointestinal tract; colorectal cancer; ulcerative colitis; haemorrhoids.

Correspondence: Dr. Narayan Belbase, Department of Surgical Gastroenterology, College of Medical Sciences, Bharatpur, Chitwan, Nepal. Email: narayan_299@yahoo.co.nz. Phone: +977-9845113139. 


\section{INTRODUCTION}

Over the recent few years there has been a tremendous improvement in the diagnosis of patients with large bowel disorders due to improvement in the multi slice Computed Tomography scan (CT scan) and the fiberoptic colonoscope. ${ }^{1}$

Colonoscopy is the preferred diagnostic tool to evaluate the large bowel in most patients with lower gastrointestinal symptoms, iron deficiency anemia, abnormal radiographic findings of the colon, altered bowel habits, identified polyps and diagnosis and surveillance of inflammatory bowel disease. Colonoscopy as a therapeutic tool helps to treat colonic obstruction by endoscopic balloon dilation or endoscopic colonic stent, hemostasis by endoscopic endoclip and polypectomy. In addition, colonoscopy is considered to be the gold standard for early detection of colonic polyps and colorectal cancers. ${ }^{2}$

So we aimed to evaluate patient characteristics, common symptoms, colonoscopic findings and histopathology findings by reviewing colonoscopy procedures performed within three year period in the endoscopy unit of a tertiary care hospital at central Nepal.

\section{METHODS}

This was a retrospective study conducted at College of Medical Sciences and teaching hospital, Bharatpur, Nepal over a period of three years (January $1^{\text {st }} 2017$-December $31^{\text {st }}$ 2019). Ethical clearance was taken from institutional review committee. Census sampling method was used to retrieve the data. Patients characteristics, indications, duration of symptoms and findings were retrieved from the endoscopy record register and histopathology finding of those patients whose biopsy were taken were retrieved from the pathology department record file. Any adverse events like bleeding or perforation during colonoscopy were also noted. Those entry whose colonoscopy was incomplete due to poor bowel preparation or patient intolerance were excluded. Childrens less than 15 years, or those whose colonoscopy was done under general anaesthesia were excluded from the study. Also, those colonoscopies whose biopsy was done and biopsy report not available were excluded from the study.

The colonoscopy was done using SONOSCAPE videocolonoscope EC500T. All the patients who underwent colonoscopy were put on liquid diet 24 hours prior to colonoscopy. Polyethylene glycol (PEGLEC, 1 packet in 2 liter water followed by ingestion of 1-2litre of oral rehydration solution (ORS) bowel preparation was done on the morning of colonoscopy. Pain was managed with Inj. BUTRIM (Butorphanol) $2 \mathrm{mg}$ intramuscular and $20 \mathrm{mg}$ buscopan intravenously (45minutes-1hour) prior to colonoscopy. During the procedure heart rate and oxygen saturation was monitored using saturation probe.

Collected data was entered into Statistical Package for Social Sciences (SPSS)data software version 20.0. For descriptive statistics categorical variables were described using frequency and percentage and illustrated using appropriate graphs or charts, continuous variables were described using mean with SD or median with IQR. For inferential statistics non-parametric test like chi-square test or Fischer's exact test was used to test the association between dependent and independent variables at 95\% confidence interval: Significance level was defined as $\mathrm{p}<0.05$. 
Results

A total of 418 colonoscopy file were reviewed.

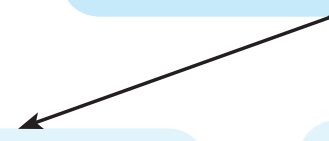

82 had incomplete colonoscopy because of poor bowel preparation or patient intolerance due to pain and 12 patients biopsy was missing so were excluded

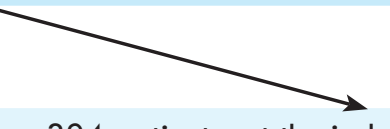

324 patient met the inclusion and exclusion criteria were enrolled and analysed.lleal intubation was achieved in $44.4 \%$ patients,normal colonoscopy was seen in $37 \%$ patients and complication in the form of lower $\mathrm{Gl}$ haemorrhage that did not required any intervention was seen in

$1.85 \%$ patients. The other findings are illustrated in tables below.

Figure 1. Flow chart of the study

The findings of the study are as shown in table 1 , 2,3 and 4 . The mean age of the study population was $48.77+/-17.35$ years, Range $15-93$ years. The most common indication for colonoscopy was pain abdomen with mucus in stool in $25.3 \%$ patients followed by bleeding per rectum in $21.3 \%$ patients. Ileal intubation was achieved in $44.4 \%$ patients.Colonoscopy was normal in $37 \%$ patients. Other than normal colonoscopy the most common findings were Haemorrhoids in $20.1 \%$ patients and inflammatory or ulcerative lesions in $17.6 \%$ patients.Colorectal malignancy was seen in $6.48 \%$ patients. Pain abdomen was not included as a study variable and hence the only complication seen was colorectal bleeding in $1.85 \%(\mathrm{n}=6)$ patients and that too was secondary to colorectal biopsy and it was subtle.

Colonoscopic biopsy was done in 114 patients. The common biopsy findings were ulcerative colitis in $12.7 \%$, adenomatous polyp in $6.8 \%$, adenocarcinoma in $6.5 \%$ of the total study patients. The most common tumor grade was well differentiated adenocarcinoma seen in $57.14 \%$ of colorectal carcinoma.

From the table 4 we can see that poorly differentiated carcinoma was found more in the younger age group whereas well differentiated carcinoma more in the elderly age group.

Ulcerative Colitis was significantly found to be in age less than or equal to 40 years ( $p$-value 0.0001), colorectal carcinoma was more in the age group $>40$ years and this was statistically significant with p-value 0.036 .

Males were more commonly affected with colorectal cancers than femaleswhich was satistically significant ( $\mathrm{p}-=0.03$ ).

\begin{tabular}{|l|l|}
\hline \multicolumn{2}{|l|}{ Table 1. General characteristics and indications. } \\
\hline Characteristics & $48.77+/-17.35$ \\
\hline AGE (+/- STD) in years & $15-93$ years \\
\hline Age range & \\
\hline Gender (percentage) & 188 (58\%) \\
\hline Male & 136 (42\%) \\
\hline Female & $1.38: 1$ \\
\hline M:F & 25.3 \\
\hline Indications for colonoscopy (percentage) \\
\hline Pain abdomen with mucus in stool & 21.3 \\
\hline Bleeding per rectum & 12 \\
\hline Pain abdomen with altered bowel habits & 12 \\
\hline Pain abdomen with bleedin per rectum & 9 \\
\hline Alterd bowel habits & 7.4 \\
\hline Pain abdomen only & 6.5 \\
\hline Constipation & 5.9 \\
\hline Pain abdomen with weight loss & 3.4 \\
\hline Evaluation of anemia & 3.1 \\
\hline Painful defecation & 2.8 \\
\hline H/o colonic carcinoma/polyposis coli & 2.5 \\
\hline USG/CECT findings prior to colonoscopy (percentage) \\
\hline Not done & 80.6 \\
\hline USG/CECT s/o bowel wall thickening & 16.7 \\
\hline USG/CECT s/o bowel mass & 2.8 \\
\hline
\end{tabular}


Table 2. Colonoscopic findings and histopathological findings.

\section{Colonoscopic findings (percentage)}

\begin{tabular}{|l|l|}
\hline Normal & 37 \\
\hline Haemorrhoids & 20.1 \\
\hline Inflammatory/ulcerative lesions & 17.6 \\
\hline Colorectal polyps & 7.1 \\
\hline Multiple colonic polyps & 1.5 \\
\hline Recto-sigmoid mass & 4.3 \\
\hline $\begin{array}{l}\text { Carcinoma ascending colon } \\
\text { caecum }\end{array}$ & 1.2 \\
\hline $\begin{array}{l}\text { Carcinoma splenic flexure and descending } \\
\text { colon }\end{array}$ & 0.9 \\
\hline Angiodysplasia colon & 2.5 \\
\hline Ileo-caecal tuberculosis & 2.2 \\
\hline Diverticulitis/diverticulosis & 2.2 \\
\hline Chronic fissure in ano & 2.2 \\
\hline Radiation induced proctitis & 2.2 \\
\hline Rectal ulcer & 0.6 \\
\hline Histopathology findings (percentage) & \\
\hline Not required & 64.8 \\
\hline Ulcerative colitis & 12.7 \\
\hline Adenocarcinoma & 6.5 \\
\hline Non-specific colitis & 2.2 \\
\hline Tuberculosis & 6.8 \\
\hline Adenomatous polyp & 1.9 \\
\hline Villous polyp & 0.3 \\
\hline Lipoma & \\
\hline Tumorgrade(n & \\
\hline
\end{tabular}

Tumor grade ( $n=21$ adenocarcinoma) (percentage)

Well differentiated adenocarcinoma 57.14

Moderately differentiated
adenocarcinoma

Poorly differentiated adenocarcinoma
Table 3. Correlation between different parameters.

Age subgroup and ulcerative colitis

\begin{tabular}{|l|l|l|}
\hline Age subgroup & $\begin{array}{l}\text { Frequency of } \\
\text { ulcerative colitis }\end{array}$ & -value \\
\hline$</=40$ years & 26 & \multirow{2}{*}{0.0001} \\
\hline$>40$ years & 15 & \\
\hline
\end{tabular}

Age subgroup and colorectal carcinoma

\begin{tabular}{|l|l|l|}
\hline Age subgroup & $\begin{array}{l}\text { Frequency of } \\
\text { colorectal carcinoma }\end{array}$ & $p$-value \\
\hline$</=40$ years & 4 & 0.03 \\
\hline$>40$ years & 17 & \\
\hline
\end{tabular}

\section{Sex and colorectal carcinoma}

\begin{tabular}{|l|l|l|}
\hline sex & $\begin{array}{l}\text { Frequency of } \\
\text { colorectal carcinoma }\end{array}$ & p-value \\
\cline { 1 - 2 } Male & 17 & 0.038 \\
\cline { 1 - 2 } Female & 4 & \\
\hline
\end{tabular}

Table 4. Age group and tumor grade.

\begin{tabular}{|c|c|c|c|}
\hline $\begin{array}{c}\text { Age } \\
\text { group }\end{array}$ & $\begin{array}{c}\text { Well } \\
\text { differentiated }\end{array}$ & $\begin{array}{c}\text { Moderately } \\
\text { differentiated }\end{array}$ & $\begin{array}{c}\text { Poorly } \\
\text { differentiated }\end{array}$ \\
\hline $\begin{array}{c}</=40 \\
\text { years }\end{array}$ & 0 & 1 & 3 \\
\hline $\begin{array}{c}>40 \\
\text { years }\end{array}$ & 12 & 5 & 0 \\
\hline
\end{tabular}

\section{Discussion}

Diagnostic colonoscopy is indicated for evaluation and recognizes the signs and symptoms of lower gastrointestinal disorders. The common symptoms that need colonoscopy tobe evaluated and recognized are lower gastrointestinal bleeding, iron deficiency anemia, unexplained changes in bowel habits (e.g., chronic constipation and diarrhea), polyps and Inflammatory Bowel Diseases (IBD). ${ }^{2}$

In the present study the mean age of the study population was $48.77=+/-17.35$ years. Most of the patients $50.92 \%(n=165)$ were in the age group 41-70 years. The male to female ratio was 1.38:1(58\% males and $42 \%$ females). In a similar 
study from Iran by Bafandeh et al., ${ }^{3}$ the mean age of the patients was 47.10 years with male predominance $(53.48 \%)$ and $M: F$ ratio was 1.15:1.

The common indications for colonoscopy in the present study was pain abdomen (with or without altered bowel habits, mucus, blood in stool and weight loss) in $52.8 \%$ followed by per rectal bleeding in $21.3 \%$, altered bowel habits in $7.5 \%$ and constipation in $5.9 \%$ patients. In a study by Bafandeh et al., ${ }^{3}$ the common indications for colonoscopy were abdominal pain (41.2\%) rectal bleeding $(31.8 \%)$ and constipation in $8.13 \%$ patients.

The percentage of normal colonoscopy was 37\% in the present study.In different colonoscopy study done by Bafandeh et al., ${ }^{3}$ HN Dinesh et al., ${ }^{4}$ and Celebi et al., ${ }^{5}$ normal colonoscopy ranged from $25.68 \%$ to $46.6 \%$.

The common findings in the present study were Haemorrhoids in $20.1 \%$, inflammatory or ulcerative lesions in $17.6 \%$ patients, colonic polyps in $8.6 \%$ and colorectal malignancy in $6.48 \%$ patients. Ileo-caecal tuberculosis was seen in $2.2 \%$ patients. On histopathology $12.7 \%$ patients were found to have ulcerative colitis and $4.9 \%$ patients had non-specific colitis. Dinesh $\mathrm{HN}$ et al., ${ }^{4}$ in a retrospective study from india in 580 colonoscopic analysis found haemorrhoids in $23 \%$, non-specific colitis in $12.75 \%$, ileo-caecal tuberculosis in $10.86 \%$,colonic polyps in $14.4 \%$ and colorectal carcinoma in $7.06 \%$ patients. ${ }^{4}$ Similarly in a study conducted by Chaudhary $S$ et al., ${ }^{6}$ from Nepal found ulcerative colitis in $10 \%$, colorectal carcinoma in $8.33 \%$ and colonic polyps in $6.67 \%$ patients.

When association between age and Ulcerative colitis was analysed in the present study ulcerative colitis was more common in the age group 21-40 years. This finding is comparable with the mean age of diagnosis of ulcerative colitis at 29.9 years and most common age group of ulcerative colitis being 17-40 years as shown by Quezada SM et al. ${ }^{7}$

Colonoscopy is the best screening test for early detection of colorectal cancer (CRC). CRC is the third most prevalent cancer in men and the second in women; accounting for $8.5 \%$ $(n=693,933)$ of all cancer deaths worldwide. ${ }^{8}$

The highest increase in the incidence of CRC is in the Eastern Europe and Asia. ${ }^{2}$ The incidence of CRC is uncommon before age 40 but rises progressively by the age of 70 . The lifetime occurrence for patients at average risk is $5 \%$, with $90 \%$ of cases occurring after age 50 . In the present study also we found $>80 \%$ colorectal cancers in age $>50$ years and the incidence of colorectal cancer in males was (>80\%).

Worldwide, studies on colorectal cancer have documented distinct differences in disease characteristics of younger and older patients in terms of stage, grade, location of tumours and survival. The younger patients present with a more aggressive disease, are advanced in stage with unfavourable histopathological findings. In our study also we found poorly differentiated colorectal carcinoma more in the age group $</=$ 40 years. $^{9}$

Colonoscopy is a highly sensitive and specific procedure and relatively safe with a low incidence of serious complications. ${ }^{10}$

Diagnostic colonoscopy caused a complication rate of nearly $0.5 \%$, which rose to $1 \%$ when polypectomy was added, with hemorrhage $(0.2 \%)$ and perforation $(0.1 \%)$ being the principal complications, with no colonoscopy-related mortality. ${ }^{11}$

Smith $^{12}$ in 20,139 colonoscopies found overall complication rate of 0.4 per cent with diagnostic colonoscopy and 1.8 per cent with polypectomy. In the present study subtle lower GI haemorrhege was seen in $1.85 \%$ and that too was biopsy related. 


\section{CONCLUSIONS}

From this retrospective study it can be concluded that colonoscopy is a useful tool for assessing patients with lower gastrointestinal tracts with pain abdomen with mucus in stool and bleeding per rectum. Colonoscopy added with biopsy helps in seggrgation of patients with inflammatory or malignant lesions and thus prompt treatment of patients.

Limitations: Since we did not have the facility to do colonoscopy under sedation, many patients had to be excluded because they couldn't tolerate the pain. Furthermore, colonoscopy was performed by multiple consultants, hence there could have been observer bias and bias in taking decision for biopsy.

\section{ACKNOWLEDGEMENTS}

To all the patients involved in the study and to Dr. Suman Raj Baral for helping with the statistic part.

\section{REFERENCES}

1. Younis HA,Moustafa HM,Alaam MS.Value of colonoscopy in the diagnosis of lower gastrointestinal disorders. AAMJ.2003 Sep;1(3):143-55. http://www. aamj.eg.net/journals/pdf/661.pdf

2. Ashtari S,Pourhoseingholi MA,Zali RM. Overview of diagnostic and treatment colonoscopy function in gastrointestinal diseases. J Liver Res Disord Ther. 2016 Nov;2(4):113-17. doi: 10.15406/ jlrdt.2016.02.00035

3. Bafandeh $Y$,Yajdanpanah F.Distribution pattern of colorectal diseases based on 2300 total colonoscopies. Gastroenterol Hepatol Bed Bench. 2017;10(2):90-96. https://www.ncbi.nlm.nih.gov/pmc/ articles/PMC5495894/

4. DineshHN,Shashidhar HB,Prasad V. An analysis of colonoscopy findings in a tertiary care. Hospital.Int.J.Sci.Study. 2015 Oct ;3(7):211-16. doi: 10.17354/ ijss/2015/479

5. Çelebi A, Teker F, Gurler M, Koc DO1, Ozdemir AA, Ekizoglu I et al. Characteristics of the patients undergoing colonoscopy in a single center within an 8-year period.. J
Gastrointest Dig Syst.2017 May;7(3);1-4 . doi:10.4172/2161-069X.1000503

6. Chaudhary S, Chaudhary P,Jaiswal N,Chaurasia RK.Colonoscopy:A two year experience from western JUCMS.2013;1(3);28-32. https://doi. org/10.3126/jucms.v1i3.8761

7. Quezada SM,Cross RK. Association of age at diagnosis and Ulcerative Colitis phenotype. Dig Dis Sci. 2012 Sep;57(9);110. doi: 10.1007/s10620-012-2081-z

8. Ferlay J, Soerjomataram I, Dikshit R, Eser S,Mathers C,Rabelo $M$,et al. Cancer incidence and mortality worldwide: sources, methods and major patterns in GLOBOCAN 2012. Int J Cancer. 2015;136(5):359-386. doi: 10.1002/ ijc. 29210

9. Lashkar RS,Talukdar FR,Mondal R,KannanR, Ghosh SK. High frequency of young age rectal cancer in a tertiary care centre of southern Assam, North East India. Indian J Med Res. 2014 Feb; 139(2): 314-318. https://www.ijmr.org.in/ article.asp?issn=09715916;

10. Bowles CJ, Leicester R, Romaya C, Swarbrick E, Williams CB, Epstein O. A prospective study of colonoscopy 
practice in the UK today: Are we adequately prepared for national colorectal cancer screening tomorrow? Gut. 2004 Feb;53(2):277-83. doi: 10.1136/ gut.2003.016436.

11. Moustafa HM, Alaam MS, Younis HA, Eid KA, Hamed AMM, El-Adl AHR. Value of colonoscopy in diagnosis and management of lower gastrointestinal disorders. AAMJ. 2008 Jan; 6(1):79-92. http://www.aamj.eg.net/inner/jarticle. aspx?aid $=1226$

12. Smith LE. Fiberoptic colonoscopy: complications of colonoscopy and polypectomy, Dis Colon Rectum; 1976 Jul-Aug ;19(5):407-412. doi: 10.1007/ BF02590825.

Citation: Belbase N, Karki M, Dewan K, Mishra R. Demographic Profile of Patients Undergoing Colonoscopy at a Tertiary Care Centre in Central Nepal. JCMS Nepal. 2021 ; 17(1); 16-22. 